\title{
Formação de estratégias em Programa de Pós-Graduação em Administração
}

\section{Strategy formation in a Graduate Management Studies Program}

\author{
LORENNA KAROLLY SANTOS DA SILVA* \\ REGINA COELI LAFAYETTE NEVES** \\ LILIAN SOARES OUTTES WANDERLEY*** \\ MANOLITA CORREIA LIMA***
}

\section{RESUMO}

Ao assumir o conceito de estratégia como o de direção para atingir objetivos (MINTZBERG; AHLSTRAND; LAMPEL, 2010), sua adoção se constitui como relevante para qualquer tipo de organização (MOORE, 2000). É pertinente compreender o modo como uma instituição concebe e trabalha suas estratégias e nesse âmbito emergem as universidades, marcadas pela complexidade e multifuncionalidade (CUNHA, 1996). Assim sendo, este é um estudo de caso com abordagem qualitativa, cujo objetivo é o de compreender como se deu o processo de formação das estratégias em um programa de pós-graduação em Administração no Brasil, desde a sua criação em 1994 até os seus 20 anos de atividades em 2014. Para tanto, empregou-se o modelo proposto por Pettigrew (1987), que se apoia em três dimensões básicas em que foram descritas as principais fases da trajetória do programa de pós-graduação abordado, atentando para as razões que levaram à mudança (contexto), como elas ocorreram (processo) e que estra-

\footnotetext{
* Universidade Federal de Pernambuco. lorennasantosadm@gmail.com .

** Universidade Federal de Pernambuco. rcln6@yahoo.com.br .

*** http://orcid.org/0000-0002-8608-2750. Universidade Federal de Pernambuco - UFPE. lilian.wanderley@ufpe.br .

**** Escola Superior de Propaganda e Marketing - ESPM/SP. mclima@espm.br .
} 
tégias foram implementadas (conteúdo) no período analisado. Os resultados indicaram que o processo de formação das estratégias recebeu considerável influência das mudanças provocadas pelo contexto externo -o processo se mostrou deliberado e emergente. Palavras-chave: Estratégia. Formação de estratégias. Pettigrew. Pós-graduação em Administração. Mudança.

\section{Abstract}

From the concept of strategy as the direction to achieve objectives (MINTZBERG; AHLSTRAND; LAMPEL, 2010), accepted as relevant to any type of organization (MOORE, 2000), it is pertinent to understand how an institution conceives and works out its strategies, and in this context, the universities, characterized by complexity and multi-functionality (CUNHA, 1996). Thus, this is a case study with a qualitative approach, whose objective is to understand how the process of strategy formation took place in a Postgraduate Program in Management in Brazil, from its creation in 1994 until its 20 years in 2014. For this, the model proposed by Pettigrew (1987), based on the model proposed by Pettigrew (1987), which is based on three basic dimensions: addressing the reasons for change (context), how they occurred (process) and what strategies were implemented (content) in the analyzed period. The results indicated that the strategy formation process received considerable influence from the changes caused by the external context -the process was deliberate and emergent.

Keywords: Strategy. Strategy Formation. Pettigrew. Higher Education in Management. Change.

\section{INTRODUÇÃo}

Ao se buscar uma definição para a palavra estratégia no arcabouço teórico que versa sobre a temática é possível encontrar múltiplos conceitos, os quais procedem de diferentes áreas do conhecimento. Os autores Mintzberg e Quinn (2001) concordam não haver consenso e argumentam que predomina a ideia de que a origem do significado da palavra estratégia é o âmbito militar. A adoção do termo no campo da Administração, como área de investigação científica ocorreu a partir da década de 1960 com os trabalhos de autores como Chandler (1962), Ansoff (1965) e Andrews (1971). 
Isto posto, o conceito de estratégia admitido para este trabalho é o de direção para atingir objetivos (MINTZBERG; AHLSTRAND; LAMPEL, 2010). Quanto à relevância do emprego das estratégias, Moore (2000) argumenta que é um elemento significativo para qualquer tipo de organização, além de funcionar como um ponto de ligação entre o mundo interior e o ambiente exterior no qual tudo o mais se opera.

Torna-se relevante compreender o modo como uma instituição concebe e trabalha suas estratégias, pois, como advogam Gomes e Meyer Jr. (2011), a formação de estratégias tem se constituído um tema de crescente interesse na literatura da área e novas reflexões e pontos de vista são necessários para melhor entendimento no assunto. Um modelo apropriado para esse tipo de análise, sendo considerado como referência para os estudiosos da área (DE WIT; MEYER, 2004; MINTZBERG, AHLSTRAND; LAMPEL, 2010), é o de Pettigrew (1987), que se apoia em três dimensões básicas: o contexto (interno e externo); o conteúdo e o processo, no qual se respaldou o presente estudo.

O contexto externo refere-se ao ambiente social, econômico e político da instituição a ser examinada; o contexto interno refere-se à estrutura, cultura e contexto político. Já o processo diz respeito a como as transformações ocorreram e o conteúdo, por fim, trata das estratégias implementadas (PETTIGREW, 1987).

Por sua vez, ao guardar diferenças marcantes (MINTZBERG; ROSE, 2003), tais como a complexidade e multifuncionalidade (CUNHA, 1996), as universidades surgem como importante objeto de estudo. Estas são caracterizadas pela não dissociação das atividades de ensino, de pesquisa e de extensão; são instituições pluridisciplinares de formação dos quadros profissionais de nível superior, de pesquisa, de extensão e de domínio e cultivo do saber humano (PINTO; MOTTER JUNIOR, 2012).

Contemplando a realidade do ensino de pós-graduação em Administração no Brasil, conforme Martins (1989), a partir da década de 1970 os cursos de graduação nessa área se consolidaram no país. E, após sua autonomização - definição do currículo do curso e da criação da categoria de técnico em Administração - vários progra- 
mas de pós-graduação foram criados em todo território nacional (KERCH, 2013).

Assim, como locus de investigação foi selecionado o Programa de Pós-Graduação em Administração (PROPAD) da Universidade Federal de Pernambuco (UFPE). No tocante à UFPE, a mesma iniciou suas atividades em 11 de agosto de 1946 e no decorrer dos anos vem consolidando seu papel na promoção de conhecimento e desenvolvimento de pessoas.

O programa foi concebido em 1994 com a denominação de Curso de Mestrado em Administração da Universidade Federal de Pernambuco (CMA/UFPE). Em 2000 ele passou a ser chamado pelo atual nome, quando expandiu a oferta de cursos e começou a oferecer também Doutorado em Administração (UFPE, 2017).

Nessa perspectiva, este estudo objetiva compreender como se deu o processo de formação das estratégias do PROPAD/UFPE, desde a sua criação em 1994 até os seus 20 anos de existência (até 2014).

\section{FORMAÇÃo DE ESTRATÉGIAS E MUDANÇA ESTRATÉGICA}

A incorporação do termo estratégia no campo da Administração, como área de investigação científica, ocorreu na década de 1960 com os trabalhos de autores como Chandler (1962), Ansoff (1965) e Andrews (1971). Desde a origem até sua popularização nas décadas de 60 e 70 o entendimento do termo passou por uma sucessão de redefinições. Como afirma Hambrick (1980), a estratégia é um conceito multidimensional e situacional - o que dificulta que se chegue a um consenso.

Nessa direção, como apontam Mintzberg, Ahlstrand e Lampel (2010), a estratégia pode assumir diversas formas, tais como: a) plano -direção, guia ou curso de ação para o futuro; b) padrão - isto é, coerência em comportamento ao longo do tempo, olhar o comportamento passado; c) posição - diz respeito a como se está localizado no ambiente ao qual está inserido; d) perspectiva -maneira de se fazer as coisas, de compreender o mundo; e e) truque - manobra específica para ludibriar um oponente. Assume-se nesse estudo o conceito de estratégia como plano.

Independente da corrente teórica e das diferentes caracterizações encontradas sobre o que é estratégia, tratar de como elas são formadas é assunto relevante no campo da Administração devido à 
crença de que o futuro pode ser alcançado a partir do presente e as experiências de sucesso já obtidas pelas organizações substanciam esse pensamento (ARAÚJO; GONÇALVES, 2011).

A maneira pela qual as estratégias surgem e se implementam não é um processo idêntico em todas as organizações, resultando antes de uma conjugação de fatores externos (características e condições do meio ambiente) e de condições internas (capacidades materiais e humanas) que configuram cada situação, particularmente (NICOLAU, 2001).

A formação das estratégias pode ser entendida sob duas principais abordagens: (I) sob a perspectiva futura ou estratégia pretendi$\mathrm{da}$, que trata da iniciativa como planejamento e (II) sob a perspectiva passada, das estratégias realizadas, sendo definidas num padrão, num fluxo de decisões (MINTZBERG, 1989).

Os autores Mintzberg; Ahlstrand e Lampel (2010) reforçam as estratégias como deliberadas (pretendidas e realizadas), não realizadas e emergentes (padrões são realizados sem intenção). Uma estratégia pode emergir como resposta a uma situação em evolução ou ser introduzida deliberadamente por meio de um processo de formulação seguido de implementação. A ideia está apresentada na ilustração 01 , de modo a facilitar o entendimento.

Ilustração 01 - Estratégias Deliberadas e Emergentes

Fonte: Adaptado de Mintzberg; Ahlstrand e Lampel (2010)

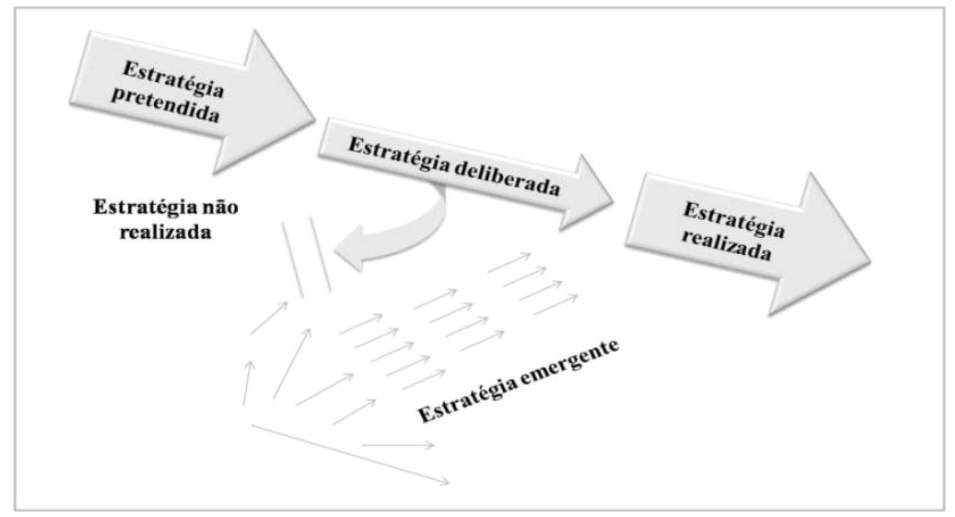


Independentemente de ser de natureza deliberada ou emergente percebe-se no processo de formação das estratégias a importância do padrão de decisões e consistência no comportamento (SALAZAR; MORAES; LEITE. 2016).

Contudo, a principal tensão da formação da estratégia é ter que antever um futuro imprevisível, configurando a dualidade de querer desenhar o porvindouro, porém, adaptando-se aos desdobramentos da realidade (TASCA; COSTA, 2015). O grande desafio do processo de elaboração de estratégias é perceber as alterações, as descontinuidades sutis que podem determinar o futuro (MINTZBERG; QUINN, 2001).

Por sua vez, a mudança está inserida no processo de formação das estratégias (DE WIT; MEYER, 2004; MINTZBERG, AHLSTRAND; LAMPEL, 2010). Ciente disso, Quinn (1980) argumenta que a estratégia não é um processo linear. Na mesma vertente, os autores Mintzeberg, Lampel, Quin e Ghoshal (2006) corroboram quando defendem que estratégia é sobre mudança e não sobre a continuidade.

As mudanças estratégicas lidam com a criação de novas configurações entre as organizações e seus ambientes (DE WIT; MEYER, 2004). Em virtude da importância de se considerar a mudança como um fator de grande influência no processo de formulação estratégica, diferentes autores já se dedicaram a ampliar seus conhecimentos sobre esse fenômeno (MINTZBERG; AHLSTRAND; LAMPEL, 2010), razão pela qual existem diferentes abordagens da expressão "mudança estratégica".

Tais alterações podem ser um processo fragmentado, evolucionário e intuitivo (QUINN, 1980). A mudança estratégica pode ocorrer por meio de saltos quânticos, isto é, de forma revolucionária e com alterações drásticas nos padrões existentes (MILLER; FRIESEN, 1982), bem como ainda ser um longo e complexo processo gradual (PETTIGREW, 1987). Cada organização irá lidar com a mudança de um modo particular (QUINN, 1980). Compreendê-la é importante para interpretar o contexto no qual a organização atua e como tal aspecto pode interferir na definição das estratégias.

Dos modelos apresentados destaca-se o de Pettigrew (1987), que acabou por servir de base conceitual e metodológica para o presente estudo. Os trabalhos de Andrew Marshall Pettigrew, desde 
sua elaboração até os dias atuais, têm se constituído como referência na literatura a esse respeito (CAVALEIRO; BARROS NETO, 2016). O modelo proposto pelo estudioso (1987) consegue explicar como e porque as organizações mudam e formulam suas estratégias dentro de uma perspectiva longitudinal, visto que envolve a interação contínua entre o contexto, o processo e o conteúdo das estratégias ao longo do tempo.

\section{O modelo de PetTigrew (1987)}

Os estudos de Pettigrew (1987) permitem identificar e correlacionar diferentes variáveis ligadas a mudança estratégica, a saber: contexto, processo e conteúdo. Sua perspectiva é também defendida por De Wit e Meyer (2004), que destacam ser fundamental considerar a complexidade desse eixo tridimensional, cujas grandezas estratégicas interagem entre si.

A dimensão contexto refere-se ao "porquê" da mudança e está subdivida em contexto externo (ambiente político, legal, econômico, social) e contexto interno (estrutura, cultura, políticas existentes na própria organização) (PETTIGREW, 1987). Mesmo sob interferência ambiental a organização é capaz de definir suas ações e estratégias, ainda que limitadas pelo contexto (PETTIGREW, 1987). E não somente o contexto externo provoca ingerência nas escolhas estratégicas, pois os membros da organização - com seus paradigmas, influenciados pelo contexto interno - realizam essas escolhas (JOHNSON, 1992; GOHR; SANTOS, 2011).

O processo significa "como" deve acontecer a mudança - são as ações, as reações e as interações das partes interessadas na mudança, na medida em que se procura modificar a organização de um estágio presente para uma fase futura (PETTIGREW, 1987; BULGACOV; SOUZA; PROHMANN; COSER; BARANIUK, 2007). A abordagem de Pettigrew (1987) caracteriza-se por uma clara descrição do processo a ser examinado dentro de uma perspectiva histórica.

Por sua vez, o conteúdo refere-se ao "que" da mudança, respeito às áreas particulares de alteração que estão sob análise (PETTIGREW, 1987). Uma organização pode buscar modificar a tecnologia, seu posicionamento, sua cultura organizacional. O ponto de partida para a mudança estratégica é a noção de que a formulação do con- 
teúdo de qualquer nova estratégia implica em gerir seu contexto e processo (PETTIGREW, 1987).

O conteúdo é tido como difícil de ser classificado porque envolve a subjetividade dos indivíduos ou grupos tomadores de decisão. As pessoas possuem diferentes valores utilizados para a construção das decisões estratégicas, razão pela qual o conteúdo da mudança é particular para cada organização (CUNHA, 1996).

A subseção seguinte irá abordar o desenvolvimento da pós-graduação no Brasil e também a importância de se trabalhar a gestão estratégica em instituições de ensino superior. Vale destacar que ao utilizar o vocábulo "organização/ões" para designar as instituições educacionais de ensino superior, as universitárias, não se pretende desconsiderar a riqueza de olhares com os quais se compreende essas instituições, mas admite-se o conceito de Baldridge (1982), no qual as universidades são organizações complexas, portadoras de objetivos, sistemas hierárquicos e estruturas, diferenciadas das demais instituições, tendo a função de promover a educação superior, a pesquisa e a extensão, além de serem aglutinadoras do saber produzido pela humanidade.

\section{Gestão estratégica na Pós-Graduação em Administra- ÇÃo NO BRASIL}

O Parecer no 977/65 do Conselho Federal de Educação fundamentou o sistema de pós-graduação brasileira em três pilares: a) a formação de docentes para atender a expansão do ensino superior, capazes de elevar o nível de qualidade do ensino; b) a preparação de pesquisadores; e c) o treinamento de profissionais para a necessidade de desenvolvimento do país nos diversos setores (BRASIL, 2005).

Nessa perspectiva "os cursos de pós-graduação foram estruturados em níveis e finalidades diferenciados: stricto e lato sensu" (SCARPIN; DOMINGUES; SCARPIN, 2008, p. 5). Entende-se como pós-graduação stricto sensu os cursos de mestrado e doutorado, e a pós-graduação lato sensu pode ser definida como o curso que se segue à graduação, seja ele de qualquer natureza, sendo representada pelos cursos de especialização (MONTEIRO, 2008).

Como relatam Waiandt e Fischer (2013), a partir da década de 1970 vários cursos de mestrado foram criados no país, sendo que o 
primeiro mestrado no campo da Administração data de 1967 e foi ofertado na área de Administração Pública, pela Escola do Rio de Janeiro/FGV.

No nível de doutorado os primeiros cursos foram oferecidos na década de 1970: em 1975, pela Faculdade de Economia e Administração, da USP; na área de Administração, em parceria com a Federação das Indústrias e a Associação do Comércio de São Paulo; e em 1976, pela Escola de Administração de Empresas de São Paulo/ FGV, na área de Administração de Empresas. Um ano depois foi criado o primeiro doutorado em Administração Pública pela FGV/ RJ (WAIANDT; FISCHER, 2013).

A pós-graduação tem contribuído valiosamente para o melhor conhecimento dos problemas que emergem nos mais variados âmbitos da nossa realidade e para a qualificação de expressivo quadro de profissionais nas áreas de ensino, gestão e pesquisa (SEVERINO, 2006).

Sobre a gestão dessas organizações atribui-se que no Brasil é baseada na improvisação, nas indefinições e na ausência de planejamento; e no caso das instituições públicas universitárias, os gestores ou gerentes universitários (reitores, pró-reitores, diretores de unidades, chefes de departamento, coordenadores de curso, entre outros responsáveis pela parte acadêmica e administrativa), papel desempenhado em grande parte pelos próprios docentes, que por sua vez, nem sempre possuíam uma preparação formal para exercer a função administrativa, e em geral, aprendiam já no exercício do cargo, cada um com seus próprios caminhos ou maneiras para gerenciar (SILVA; MORAES, 2002; MARRA; MELO, 2003).

A partir da Revolução Universitária ocorrida na década de 1960, a universidade pública passa por um processo de reestruturação, principalmente, pela expansão do ensino superior; aumento do controle externo (avaliação institucional, provão, avaliação da CAPES, padrões numéricos de desempenho, entre outros); discussão da autonomia universitária; redução de recursos governamentais; e implantação da administração pública gerencial (MARRA; MELO, 2003).

A lei federal de 1968, direcionada às universidades produziu efeitos paradoxais no ensino superior brasileiro, por um lado, modernizou uma parte significativa das universidades federais e determinadas instituições estaduais e confessionais, que incorporaram 
gradualmente as modificações acadêmicas propostas pela Reforma (MARTINS, 2009). Em contrapartida, a administração pautada num modelo burocratizado, por força de lei, demandava também que as universidades seguissem o molde indicado pelo governo central, marcado pela rigidez dos procedimentos e a existência de normas e regulamentos que direcionam seu gerenciamento (SILVA; MORAES, 2002).

Assim, a universidade modela seus processos administrativos, mediante algumas condições favoráveis e outras dificultadoras, para seus ocupantes dos cargos de chefia, que por meio de práticas gerenciais, decisões e ações, viabilizam o alcance dos objetivos institucionais (MARRA; MELO, 2003).

Ainda sobre as organizações educacionais, de acordo com Weick (1976), são tidas como sistemas frouxamente articulados, o que se constitui fator diferenciador de outros tipos de instituições. $\mathrm{O}$ fato de seus agentes compartilharem alguns poucos pontos comuns e, ao mesmo tempo, manterem sua independência e autonomia, apresenta claras implicações no desempenho destas e na forma como são conduzidas.

Em relação à complexidade, Andrade (2002) sintetiza que as universidades apresentam as seguintes características: metas institucionais definidas de maneira muito ampla, o que dificulta a definição e a operacionalização de objetivos; seus profissionais possuem elevado grau de autonomia sobre suas atividades; a complexidade de sua tecnologia impede que esta seja desenvolvida de forma padronizada e racional; sua estrutura é fragmentada e pouco sujeita a controles formais e está à mercê de conflitos de diferentes naturezas, além do fato de que seus processos de tomada de decisão encontram-se disseminados ao longo de um grande número de unidades e atores. Ademais, os autores Meyer Jr., Lopes, Zabronski e Murphy (2010) argumentam que as universidades podem contar com gestão melhor articulada com vistas ao atendimento de seus objetivos.

Na percepção de Meyer Jr. e Mugnol (2004), um dos aspectos principais da gestão das instituições de ensino superior é a formulação e o desenvolvimento de estratégias que lhes permitam se tornar mais efetivas no cumprimento de sua missão. Os autores ressaltam que as decisões, as políticas, os planos, a qualidade dos cursos, o 
desenvolvimento dos docentes, a combinação e captação de recursos, tecnologia e imagem institucional são áreas estratégicas que contribuem para o bom desempenho dessas instituições.

$\mathrm{O}$ "pensar estrategicamente" tornou-se fator relevante para guiar também as organizações que possuem caráter social na consecução de seus intentos, indistintamente de visar o lucro ou não (MOORE, 2000). A estratégia pode ser oriunda do ganho de conhecimento diário, do resultado de experiências anteriores e da evolução dentro da curva de conhecimento (BUCKLAND, 2009).

Muitas são as reflexões sobre o posicionamento estratégico adotado pelas instituições de ensino superior e acerca de que as decisões possam favorecer a sociedade de modo geral (CASARTELLI; RODRIGUES; BITTENCOURT; GARIBOTTI, 2010).

Com o objetivo de colaborar com as discussões acerca das estratégias no âmbito das Instituições de Ensino Superior (IES) brasileiras, inúmeros autores desenvolveram suas pesquisas voltadas a essa temática por meio de estudos de casos: Macedo (2011) e Souza et al.(2012). Eles sugerem que diversos estudos sigam sendo realizados em outras Instituições de Ensino Superior, com o objetivo de formar massa crítica que venha a permitir melhor compreensão sobre a formação de estratégia em IES, o que converge com os objetivos do presente estudo.

\section{Procedimentos metodológicos}

O presente estudo é de caráter qualitativo, situado no paradigma interpretativista. A abordagem qualitativa entende que a realidade é subjetiva e socialmente construída (AUGUSTO; SOUZA, DELLAGNELO; CARIO, 2013; VIEIRA; RIVERA, 2012; CRESWELL, 2010; MINAYO, 2010; FLICK, 2009). Aborda e compreende o mundo real, descreve e por vezes explica os fenômenos sociais de diferentes maneiras: analisando experiências de indivíduos e grupos, examinando interações e comunicações que estejam se desenvolvendo e investigando documentos ou traços semelhantes de experiências ou interações (FLICK, 2009; CRESWELL, 2010; MINAYO, 2010; STAKE, 2011).

$\mathrm{O}$ estudo de caso qualitativo justifica-se para a presente investigação em função da particularidade que envolve o objeto de estudo, 
o Programa de Pós-Graduação em Administração (PROPAD/UFPE). Caracteriza-se como estudo de caso a observação detalhada de um contexto, de um indivíduo, de uma fonte de documentos ou de um acontecimento específico (BOGDAN; BIKLEN, 1994). Como apontam Ludke e André (1986), o interesse por essa escolha incide naquilo que o contexto sob estudo tem de único, de particular, mesmo que posteriormente venha a ficar evidentes certas semelhanças com outros casos ou outras situações.

Em relação à direcionalidade temporal do estudo, o mesmo possui uma perspectiva longitudinal, "ex post facto" por se tratar da análise do processo de formação de estratégias ao longo do tempo. Serve para identificar o conteúdo, processo e contexto das mudanças estratégicas (PETTIGREW, 1987) na trajetória da instituição estudada, a partir da delimitação de eventos relevantes no espaço de tempo investigado, particularmente ao longo dos 20 anos (1994-2014) do PROPAD/UFPE.

A Universidade Federal de Pernambuco - UFPE - é uma das pioneiras no ensino superior em Administração no Nordeste do Brasil e dada a sua importância e de seu Programa de Pós-Graduação em Administração para o estado e para o país ela foi escolhida como locus de investigação. O Programa de Pós-Graduação em Administração (PROPAD), da Universidade Federal de Pernambuco, que oferece atualmente os cursos de Mestrado e de Doutorado, foi concebido em 1994 (UFPE, 2017).

Sobre a coleta dos dados foram empregadas a entrevista semiestruturada e a análise documental. A entrevista semiestruturada propicia o detalhamento de questões ligadas aos conceitos teóricos relacionados, tornando-se uma rica fonte de informações a partir de um processo conversacional (OLIVEIRA; MARTINS; VASCONCELOS, 2012). Isto posto, foi elaborado um guia com pontos que norteou a realização das entrevistas, e para tanto, considerou-se a experiência do pesquisador e a literatura sobre o tema (MANZINI, 2004). Para que os pontos fossem aprimorados realizaram-se entrevistas-piloto (GODOY, 2010).

Para maior robustez no material coletado também se adotou a pesquisa documental, que se caracteriza como análise valiosa para 
desvelar aspectos novos de um tema ou problema e/ou complementar as informações obtidas por outras técnicas (LUDKE; ANDRE, 1986). A escolha partiu da compreensão de que os documentos consistem numa fonte natural de informações sobre determinado contexto (LUDKE; ANDRE, 1986). Foram acessados documentos, como: relatórios de avaliação, plano de gestão, regimento interno, atas, formulários de inscrição dos discentes e outros materiais institucionais. Foi elaborada uma ficha de orientação para a análise documental.

Acerca da seleção dos sujeitos para a entrevista, a pesquisa qualitativa não se baseia no critério numérico para que tenha representatividade (MINAYO, 2010). Num primeiro contato com o campo, em conversas informais com integrantes do PROPAD foi mapeado um conjunto de atores considerados como tendo uma participação expressiva na trajetória do referido programa.

A escolha dos entrevistados esteve alinhada aos objetivos do estudo e como critério norteador definiu-se que seriam entrevistados indivíduos que participaram e/ou ainda integram o PROPAD, inseridos na Universidade Federal de Pernambuco nos limites do recorte temporal delimitado que assumiram e/ou acumularam papéis, como: fundadores do programa, docentes, técnico-administrativos, discentes (alguns "foram"-palavra excluída representantes estudantis), chefes do Departamento de Ciências Administrativas, diretores do Centro de Ciências Sociais Aplicadas e pró-reitores. Vale ressaltar que tais papéis não se mostram mutuamente excludentes, havendo entrevistados que assumiram múltiplas funções em diferentes momentos.

Foram quinze entrevistados e como boa prática todos os participantes tiveram acesso e anuíram ao Termo de Consentimento Livre Esclarecido (TCLE). As entrevistas foram realizadas de junho a dezembro de 2016, pois os sujeitos selecionados possuíam agendas dispersas - a maioria delas em Recife/PE. É oportuno mencionar que ainda assim houve a necessidade de utilizar o Skype, aplicativo que possibilita a comunicação por voz e vídeo via internet para romper a barreira geográfica.

Um corpus desejado é aquele que reflete o conjunto das múltiplas dimensões do objeto pesquisado (MINAYO, 2010). As entrevistas exigiram 14h33m10segundos, o que rendeu 329 (trezentos e vinte e nove) páginas de transcrição. Não se buscou volume ou 
quantidade, mas a compreensão do objeto estudado até o ponto que se considerou que o conhecimento apreendido permitisse assimilar o fenômeno investigado (MINAYO, 2010) ou até que houvesse redundância nos dados obtidos (LINCOLN; GUBA, 1985).

Das diversas opções avaliadas para este estudo a análise pragmática da linguagem (WITTGENSTEIN, 1994; MATTOS, 2010) foi escolhida como a mais apropriada para o tratamento dos dados. Entendeu-se que "a análise da entrevista muito ganharia por uma aproximação à análise pragmática da linguagem, e a razão principal a favor disso é que a entrevista não estruturada ou semiestruturada realmente é uma forma especial de conversação" (MATTOS, 2010, p. 349).

A escolha deu-se por dois principais motivos: (I) a conversação humana vem sendo estudada sistematicamente há mais de meio século pela linguística e pela pragmática da linguagem (MATTOS, 2010) e (II) a análise pragmática envolve a elaboração de conclusões que vão acrescentar significação ao conhecimento de mundo e ao modelo do falante, isto é, as inferências sobre o que o entrevistado sabe, em que ele acredita, como se sente em relação aos outros, às situações, aos eventos referidos no decorrer da conversação (LINS, 2008).

Decorrente da diversidade dos grupos envolvidos no estudo, do número de entrevistas obtidas e do volume que resultou o conteúdo das transcrições tornou-se oportuno utilizar o software QSR NVIVO 10 para a análise das narrativas obtidas. Este programa de computador tem sido aplicado no campo da administração, particularmente porque o tratamento das comunicações pode ser bastante amplo conforme os objetivos e delineamento metodológicos de uma pesquisa, destarte, emerge a necessidade do emprego de técnicas computacionais. O NVIVO foi empregado para facilitar a organização dos dados, agilizar as análises (MOZZATO; GRZYBOVSKI, 2011), não eximindo a atuação ativa dos pesquisadores na adoção de um método de análise coerente e pertinente ao tema e à orientação epistemológica (ALVES; FIGUEIREDO FILHO; SILVA, 2015; MOZZATO; GRZYBOVSKI, 2011).

Na seção seguinte que apresenta e discute os dados foi construído e reconstruído reunindo conteúdos das transcrições, comple- 
mentados pela análise documental de atas das reuniões, relatórios da Coordenação de Aperfeiçoamento de Pessoal de Nível Superior (CAPES) e regimentos/resoluções internas. Pela abordagem de Pettigrew (1987) ser caracterizada por uma clara descrição do processo dentro de uma perspectiva histórica, o estudo é longitudinal ao trazer a dimensão do tempo no processo de formação de estratégias. Houve uma divisão em quatro fases que emergiram das entrevistas, subdivididas em eventos. Essas fases não foram apontadas de forma explícita pelos respondentes e sim quando das análises que destacaram os eventos como marcos episódicos. Extratos selecionados das narrativas dos entrevistados podem ser consultados em Silva (2017).

É possível considerar o modelo de Melin (1992), exposto na ilustração 02 que traz quatro abordagens para tanto: I) Eventos tipo A: o processo é uma série de eventos críticos temporais; II) Eventos tipo B: o processo é um episódio relativamente curto que pode ser de algumas semanas ou alguns anos; III) Eventos tipo C: o processo é demorado, ocorrendo uma série de épocas que podem ser longos períodos de mudança evolutivas interrompidos por curtos episódios de mudança revolucionária; e, por fim, IV) Eventos tipo D: o processo é visto como uma história biográfica contemplada desde a fundação da organização estudada até o presente momento. Para o presente estudo, optou-se pela utilização dos modelos A e B para estabelecer os eventos críticos e a abordagem tipo C, para delinear as fases, que por sua vez, nem sempre foram homogêneas. As estratégias elencadas em cada fase foram tipificas a partir da literatura, diante do que fora indicado pelos atores sociais envolvidos no programa de pós-graduação abordado. 
Ilustração 02 - Quatro Tipos de Processos por Abordagens Longitudinais

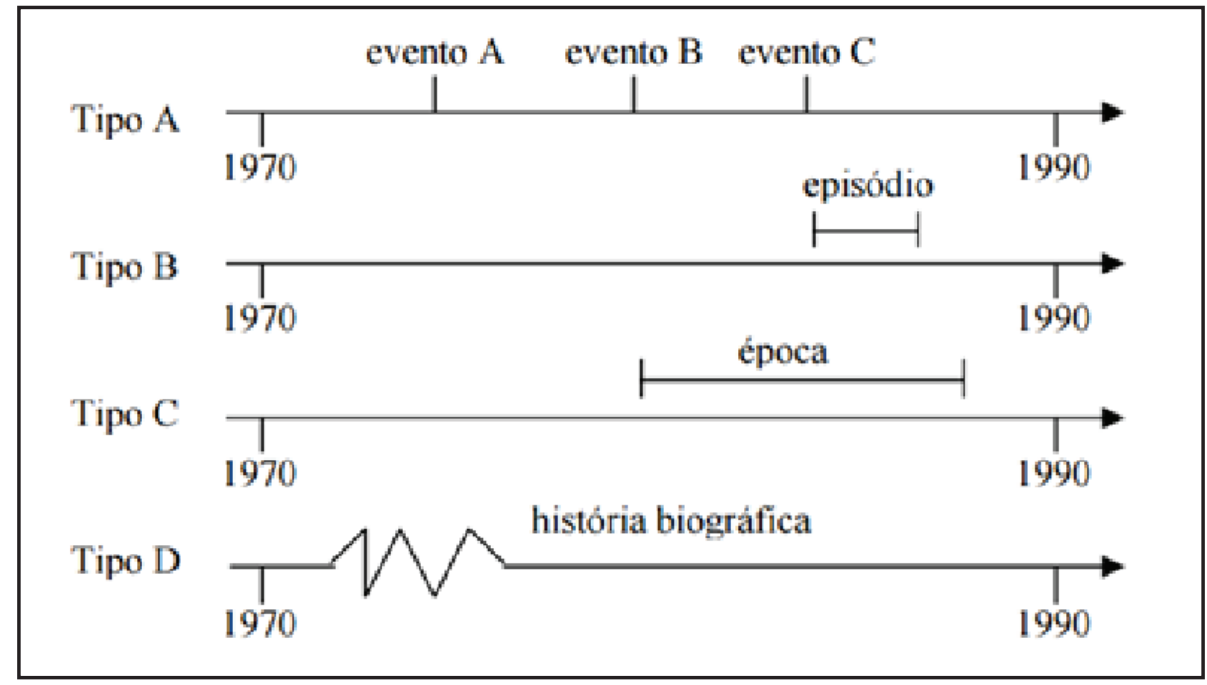

Fonte: Melin (1992, p.102)

Ainda, no emprego da pesquisa qualitativa faz-se necessário atentar para aspectos de validade e confiabilidade, no qual a validade se refere a capacidade em que os métodos utilizados conseguem alçar os objetivos propostos e a confiabilidade parte da noção de consistência, da segurança de que outro pesquisador acompanhando entende como foi realizada a pesquisa e como os resultados foram obtidos (PAIVA JUNIOR; LEÃO; MELLO, 2011).

Atentando para tais elementos, foram adotadas algumas técnicas na presente investigação. Uma delas foi a triangulação, que é um modo de institucionalização de perspectivas e métodos teóricos, buscando reduzir as inconsistências e contradições de uma pesquisa (GASKELL; BAUER, 2002). A triangulação supera as limitações de um método único, por combinar diversos métodos e dar-lhes igual relevância (CRESWELL, 2010; FLICK, 2009). Por isso, optou-se pela entrevista semiestruturada e a pesquisa documental. A triangulação torna o resultado da pesquisa profundo e rico (DENZIN; LINCOLN, 2006).

Sucedendo o processo de transcrição das entrevistas houve o feedback aos informantes, sugerido pelos autores Paiva Junior, Leão 
e Mello (2011) que corresponde à confrontação com fontes e obtenção da concordância ou consentimento dos entrevistados, sendo chamado de critério de validação comunicativa dos participantes. Cada um dos quinze entrevistados recebeu por e-mail o arquivo em formato eletrônico com a transcrição. Os retornos foram positivos e os entrevistados concederam total anuência quanto ao material que fora submetido para apreciação, não tendo havido sugestões de mudança.

\section{APRESENTAÇÃo E disCUSSÃo doS DAdOS}

Tomando como ponto de partida o modelo de Pettigrew (1987), que versa acerca da importância de se compreender os processos de estratégia na medida em que ocorrem, a trajetória do PROPAD foi dividida em quatro fases decompostas a partir dos eventos mais significativos que caracterizam cada uma delas.

Para que se chegasse a cada um dos trinta e um eventos listados e, consequente divisão das fases, houve a prospecção dos principais marcos episódicos com os entrevistados. À medida que os eventos eram apontados conseguia-se enxergar com nitidez a quebra de uma fase para outra, decorrente de mudanças provocadas por algum episódio característico.

Essas fases foram nomeadas conforme o quadro 01, a seguir.

Quadro 01 - Principais Fases Identificadas

\begin{tabular}{|l|l|l|}
\hline $\mathrm{N}^{\circ}$ & PERÍODO & DESCRIÇÃO \\
\hline FASE 1 & $(1988-1994)$ & $\begin{array}{l}\text { Eventos anteriores ao início das aulas no } \\
\text { CMA/PROPAD }\end{array}$ \\
\hline FASE 2 & $(1994-1999)$ & Início das Aulas/Instauração - CMA \\
\hline FASE 3 & $(2000-2009)$ & Estruturação e expansão - PROPAD \\
\hline FASE 4 & $(2009-2014)$ & Inflexão \\
\hline
\end{tabular}

Fonte: Elaborado pelas autoras (2018)

A primeira fase é referente a uma sequência de eventos anteriores à fundação do programa, especialmente no Departamento de Ciências Administrativas (DCA), tais acontecimentos, detalha- 
dos na subseção seguinte, ensejaram a instauração do Curso de Mestrado em Administração (CMA), posteriormente nomeado de Programa de Pós-Graduação em Administração (PROPAD. A partir da segunda fase serão analisados o contexto (interno e externo), o processo e conteúdo das estratégias adotadas pelo programa e pós-graduação da instituição.

\subsection{Fase 01: Eventos Anteriores ao CMA/PROPAD (1988- 1994)}

A primeira fase teve início em 1988, quando o Departamento de Ciências Administrativas (DCA) da UFPE experimentava um processo de profundas transformações para a pós-graduação stricto sensu em Administração. Naquela época havia poucos professores voltados às atividades de pesquisa e as iniciativas ocorriam de modo isolado. O chefe do DCA, ao perceber a lacuna existente, ofereceu apoio àqueles professores que quisessem maior qualificação e estivessem interessados em produzir conhecimento na área. Dessa forma alguns docentes saíram do estado e até mesmo do país para a realização do processo de doutoramento.

No Nordeste brasileiro três instituições de ensino disponibilizavam cursos de pós-graduação stricto sensu em Administração: a Universidade Federal da Paraíba (UFPB) oferecia mestrado desde 1976; a Universidade Federal do Rio Grande do Norte (UFRN) assegurava o curso de mestrado desde 1978 e a Universidade Federal da Bahia (UFBA) já ofertava mestrado desde 1983 e doutorado a partir de 1993. Pioneira na região, a UFBA se adiantou às demais e foi a primeira a possuir programa doutoral.

É válido apontar que em 1989 foi criado o III Plano Nacional de Pós-Graduação (PNPG) visando aprimorar o sistema (SILVA, 2010). (Não estava nas referências - adicionado). No ano de 1990 e ao longo de toda a década o campo político foi marcado pela busca da estabilidade econômica no Brasil, bem como pelos processos de reforma do Estado, que tiveram seus reflexos na educação (SANTOS; AZEVEDO, 2009).

A educação superior estava começando a experimentar um processo de expansão e regulação. Houve, por exemplo, a Criação 
das Fundações de Amparo à Pesquisa Estaduais - FAPs (1990), que buscou complementar os programas federais de fomento às atividades científicas; a formação de pesquisadores competentes, privilegiar a pesquisa básica e os interesses regionais de desenvolvimento político e tecnológico (MOROSINI, 2009). A Fundação de Amparo à Ciência e Tecnologia de Pernambuco (FACEPE) surgiu em tal período.

O ambiente era favorável para a pós-graduação no Brasil. $\mathrm{O}$ DCA da UFPE organizou uma movimentação para viabilizar a oportunidade de um mestrado em Administração e em 1994 foi reunido o núcleo composto pelos docentes fundadores do Curso de Mestrado em Administração, que, quando do retorno do processo de doutorado, submeteram e conseguiram a aprovação da proposta do CMA à Coordenação de Aperfeiçoamento de Pessoal de Nível Superior (CAPES).

\subsection{Fase 02: Início das aulas/instauração - CMA (1994- 1999)}

Com vistas a alcançar melhor entendimento de cada fase, a partir da segunda etapa dividiu-se o processo de formação de estratégias em contexto interno e externo, processo e conteúdo.

Esta fase principiou em 1994, quando as atividades para o funcionamento do programa são empreendidas, a exemplo do primeiro processo seletivo. Em janeiro de 1995 o Departamento de Ciências Administrativas (DCA) da Universidade Federal de Pernambuco deu início efetivamente às suas atividades de pós-graduação stricto sensu em Administração com as aulas do mestrado. Com o nome de CMA, estreou o então, Curso de Mestrado em Administração, posteriormente chamado de Programa de Pós-Graduação em Administração (PROPAD).

Era importante que todos os precursores em 1994 tivessem em seu registro de desenvolvimento o título de doutor e produção acadêmica regular -naquela época já estavam em atividade alguns projetos do Programa Institucional de Bolsas de Iniciação Científica (PIBIC) e bolsas de pesquisadores, mas poucos docentes possuíam formação em nível doutoral. 
O curso que se iniciou apresentava algumas características diferentes em relação à maioria dos mestrados existentes, sendo que a mais marcante delas era que se voltava principalmente para a formação de profissionais do mercado. Nas primeiras turmas a maioria dos mestrandos era composta por gerentes, empresários, consultores ou vinculados ao serviço público. Havia também aqueles que aspiravam a carreira do magistério.

As dissertações, em cujas bancas havia sempre um membro do ambiente profissional, procuravam abordar temas de interesse direto das organizações a que estavam vinculados os mestrandos. A maior parte das disciplinas acompanhava visão integrada para a prática gerencial, contribuições de várias áreas do conhecimento que ordinariamente eram estudadas como disciplinas diferentes (por exemplo, Ambiente Gerencial, Trabalho e Capitalismo no Mundo Moderno, Administração Contemporânea, Métodos Quantitativos Aplicados à Gestão). Os estudos eram voltados para os problemas das empresas a que os aspirantes a mestrandos do CMA estavam associados na fase de candidatura.

À medida que os anos passavam novos professores ingressados ou titulados entre 1997 e 1999 chegavam preparados para lecionar na pós-graduação stricto sensu com um caráter mais voltado para a cultura universitária do que para o mercado. Em 1999, o DCA formalizou o projeto para criação do curso de doutorado. A síntese dessa fase está descrita no quadro 02. 
Quadro 02 - Síntese das Dimensões da Fase 02

\begin{tabular}{|c|c|c|}
\hline \multicolumn{3}{|c|}{ FASE 02: INÍCIO DAS AULAS/INSTAURAÇÃO - CMA (1994-1999) } \\
\hline & 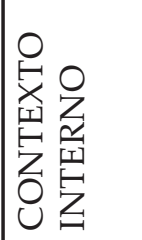 & $\begin{array}{l}\text {-O CMA inaugurou suas atividades; } \\
\text {-Boa convivência e integração; } \\
\text {-Ambiente interno desafiador; } \\
\text {-Infraestrutura pouco adequada e recursos limitados; } \\
\text {-Quantidade restrita de professores doutores. }\end{array}$ \\
\hline 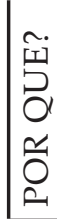 & 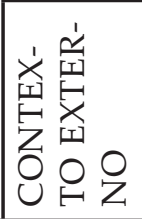 & $\begin{array}{l}\text {-Demanda reprimida por cursos de pós-graduação } \\
\text { em Pernambuco; } \\
\text {-Onda de expansão do ensino em nível de pós-gra- } \\
\text { duação; } \\
\text {-Crescimento do segmento privado de IES. }\end{array}$ \\
\hline $\begin{array}{l}\tilde{\tilde{y}} \\
\tilde{\sigma}^{\prime} \\
0\end{array}$ & 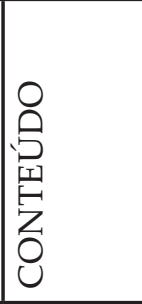 & $\begin{array}{l}\text {-Proposta inovadora de um mestrado que trazia } \\
\text { maior aproximação com o mercado; } \\
\text {-Penetração no segmento de pós-graduação em Ad- } \\
\text { ministração; } \\
\text {-Espelhamento nos cursos das regiões Sul e Sudeste; } \\
\text {-Construção de uma boa reputação; } \\
\text {-Atuação integrada às atividades do DCA/UFPE. }\end{array}$ \\
\hline & 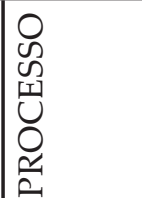 & $\begin{array}{l}\text {-Aprovação do CMA pela CAPES; } \\
\text {-Realização de processo seletivo para discentes; } \\
\text {-Viabilização das aulas; } \\
\text {-Captação de recursos. }\end{array}$ \\
\hline
\end{tabular}

Fonte: Elaborado pelas autoras (2018)

Este segundo momento finda em 1999 com a votação do Regimento Interno para o que já seria o Programa de Pós-Graduação em Administração (PROPAD). A subseção seguinte apresentará a terceira fase.

\subsection{Fase 03: Estruturação e expansão - PROPAD (2000-2009)}

Inicia-se em 2000, fase que tem duração de nove anos. Não foi possível dissociar o momento da estruturação e da expansão ocorridos no PROPAD, pois eles aconteceram simultaneamente. A partir das demandas que se apresentavam o programa ia se estruturando e consequentemente obtendo os resultados almejados. 
Houve mudanças significativas para entender a atual configuração do Programa, pois a proposta inicial que privilegiava maior contato com o mercado voltou seu foco à academia, além de exigir um novo formato em sua organização. Foi época da aprovação do doutorado e reconhecimento de uma nova designação, não era mais o Curso de Mestrado em Administração (CMA), mas o Programa de Pós-Graduação em Administração (PROPAD).

Esta terceira etapa caracteriza-se como um verdadeiro divisor de águas para o programa; estabelece um corte na história e, por conseguinte, na formulação das estratégias. Compreende-se que até aquele período o CMA buscava o reconhecimento da CAPES, por meio de uma avaliação positiva, até porque o programa precisava se efetivar. Com a implantação do PROPAD a estratégia volta-se especialmente para o crescimento, com o intuito de angariar maior visibilidade e reconhecimento diante dos pares, e, consequentemente maior pontuação na avaliação da CAPES.

Sucedendo a implantação do doutorado os objetivos do programa foram redirecionados. Ocorreu então um processo formal de concepção das estratégias com a realização do planejamento estratégico. Nesta fase a influência do contexto externo, sobretudo de aspectos voltados para a avaliação institucional, fez com que o programa tivesse que se adaptar às mudanças de modo a obter os resultados almejados (PETTIGREW, 1987). Consequentemente, houve a mescla de estratégias deliberadas e emergentes. $\mathrm{O}$ quadro 03 traz a síntese das dimensões contexto, conteúdo e processo. 
Quadro 03 - Síntese das Dimensões da Fase 03

\begin{tabular}{|c|c|c|}
\hline \multicolumn{3}{|c|}{ FASE 03: ESTRUTURAÇÃO E EXPANSÃO - PROPAD (2000-2009) } \\
\hline & 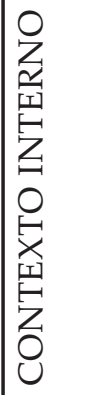 & $\begin{array}{l}\text {-O CMA passa a ser denominado de PROPAD; } \\
\text {-Melhor infraestrutura; } \\
\text {-Novos professores chegam ao PROPAD e outros se } \\
\text { aposentam; } \\
\text {-Crescimento do Programa (Nota 5), maior notoriedade. }\end{array}$ \\
\hline 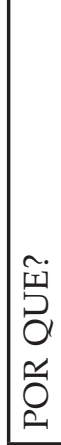 & 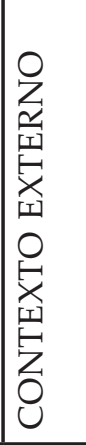 & $\begin{array}{l}\text {-Expansão do sistema de pós-graduação; } \\
\text {-Maior rigor nas métricas de avaliação da CAPES; } \\
\text {-Políticas para redução das desigualdades inter e intrar- } \\
\text { regionais no âmbito da pós-graduação do país (Mestra- } \\
\text { do Interinstitucional - MINTER e doutorado interinsti- } \\
\text { tucional - DINTER); } \\
\text {-Reflexos das mudanças nas regras previdenciárias; } \\
\text {-Estímulo à criação de grupos de pesquisa pelo Conse- } \\
\text { lho Nacional de Desenvolvimento Científico e Tecnoló- } \\
\text { gico (CNPq); } \\
\text {-Maior competição entre IES - intensificação do sistema } \\
\text { de ranqueamento. }\end{array}$ \\
\hline $\begin{array}{l}\tilde{1} \\
\tilde{0} \\
0\end{array}$ & 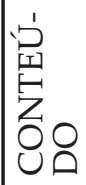 & $\begin{array}{l}\text {-Crescer, por meio da implantação do doutorado; } \\
\text {-Dar uma feição mais acadêmica ao Programa; } \\
\text {-Galgar maior conceito na avaliação da CAPES; } \\
\text {-Conferir maior visibilidade ao programa. }\end{array}$ \\
\hline$\sum_{0}^{\tilde{O}}$ & 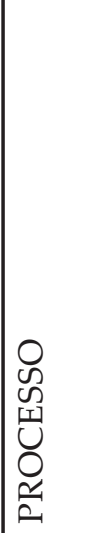 & $\begin{array}{l}\text {-Viabilização do doutorado; } \\
\text {-Maior incentivo à pesquisa/ produção; } \\
\text {-Estruturação dos processos internos; } \\
\text {-Realização de planejamento estratégico; } \\
\text {-Intensificação de cobranças para cumprimento dos } \\
\text { prazos de defesa de dissertação/tese; } \\
\text {-Implantação do Observatório de Estudos Organizacio- } \\
\text { nais; } \\
\text {-Instauração do Programa de Apoio à Publicação ( Pro- } \\
\text { gAP); } \\
\text {-Inserção da Revista Gestão.Org.; } \\
\text {-Cumprimento das exigências da CAPES (laboratório, } \\
\text { banco de teses e dissertações etc.); } \\
\text {-Concurso para novos docentes; } \\
\text {-Estabelecimento de convênios (MINTER e DINTER). }\end{array}$ \\
\hline
\end{tabular}

Fonte: Elaborado pelas autoras (2018) 
Essa terceira fase se encerra em 2009 com mudanças significativas para entender a atual configuração do programa, como será exposto na subseção seguinte.

\subsection{Fase 04: Inflexão (2009-2014)}

A última fase, a de número quatro, é intitulada "Inflexão", iniciando-se em 2009 quando do positivo resultado do triênio 20072009 e se estendendo para 2014, que é o limite final do recorte de tempo adotado. A queda da nota na avaliação CAPES referente ao triênio 2010-2012 leva os docentes do programa a repensar o curso de suas ações para o imediato futuro.

O período é marcado pela predominância de estratégias emergentes. A queda inesperada no conceito do programa exerceu influência no que tange à reorganização do mesmo, o que corrobora com a alegação de que o processo de formulação de estratégias não é uma ciência exata, pois requer experimentação e ajustes (COSTA, 2005).

De todas essas modificações decorre o aumento da competitividade interna, rupturas, ampliação da animosidade nas disputas políticas e também fragmentação. Houve crescimento significativo na diversificação nas atividades, os grupos foram se consolidando e os interesses acadêmicos, se estabelecendo.

O programa havia sido avaliado com o conceito 5 no triênio 2007-2009, recebendo indicação para o 6, contudo, em resultado da avaliação divulgado em 2013 a expectativa foi frustrada e o PROPAD recebeu nota 4 . Não apenas deixou de alcançar o resultado almejado, como também caiu na pontuação. O quadro 04 apresenta a síntese das dimensões de Pettigrew (1987), correspondentes a esta quarta fase. 
Quadro 04 - Síntese das Dimensões da Fase 04

\begin{tabular}{|c|c|c|}
\hline \multicolumn{3}{|c|}{ FASE 04: INFLEXÃO (2009-2014) } \\
\hline \multirow[b]{2}{*}{ 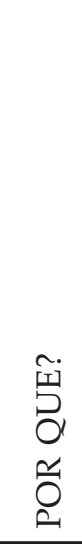 } & 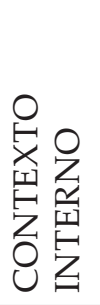 & $\begin{array}{l}\text {-O PROPAD torna-se reconhecidamente acadêmico; } \\
\text {-Amplificação nas disputas políticas, maior divisão } \\
\text { entre os docentes; } \\
\text {-O PROPAD tem avaliação 5, indicando conceito } 6 \text { pela } \\
\text { CAPES no triênio 2007-2009; } \\
\text {-O PROPAD tem avaliação } 4 \text { pela CAPES no triênio } \\
\text { 2010-2012. }\end{array}$ \\
\hline & 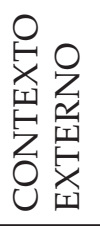 & -Mudanças abruptas nas regras de avaliação da CAPES. \\
\hline $\begin{array}{l}\tilde{\omega} \\
\tilde{D} \\
0 \\
0\end{array}$ & 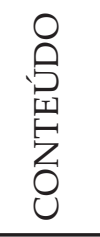 & $\begin{array}{l}\text {-Propiciar liberdade de pesquisa aos docentes que dese- } \\
\text { jam produzir; } \\
\text {-Incentivar as atividades voltadas para a internacionali- } \\
\text { zação. }\end{array}$ \\
\hline$\sum_{0}^{0}$ & 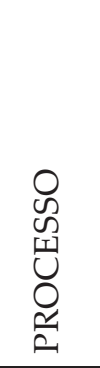 & $\begin{array}{l}\text {-Diversidade nos estudos/ pesquisas realizadas dentro } \\
\text { do PROPAD; } \\
\text {-Entrada de recurso acerca do conceito 4, atribuído pela } \\
\text { avaliação da CAPES; } \\
\text {-Reuniões acerca dos rumos do programa; } \\
\text {-Ações de internacionalização (convênios, recepção de } \\
\text { professores visitantes, participação em eventos interna- } \\
\text { cionais, etc.). }\end{array}$ \\
\hline
\end{tabular}

Fonte: Elaborado pelas autoras (2018)

A partir de então foi instalado um processo de reestruturação com vistas à retomada no conceito. A estratégia declarada foi a recuperação do melhor conceito da avaliação CAPES e ainda maiores investidas nas atividades de internacionalização. Como estratégia para essa fase cria-se ambiente de pesquisa para que não sejam tolhidos aqueles que desejam desenvolver seus trabalhos. Essa diversidade, por um lado, traz maior liberdade nas pesquisas 
e ao mesmo tempo pode gerar menor eficiência na sinergia entre os membros do programa. A seção seguinte traz as considerações finais obtidas com a investigação.

\section{CONSIDERAÇõES FINAIS}

O objetivo central do estudo foi compreender como se deu o processo de formação das estratégias do PROPAD/UFPE, desde a sua criação em 1994 até os seus 20 anos de existência em 2014.

Para alcançar o objetivo proposto as escolhas teóricas e metodológicas levaram à identificação de eventos marcantes para o programa estudado, que foram agrupados em fases dentro do período investigado. Por sua vez, essas fases foram observadas sob modelo proposto por Pettigrew (1987), atentando para as razões que levaram à mudança (contexto), como elas ocorreram (processo) e quais as estratégias implementadas (conteúdo) no período.

Referente à compreensão do movimento dos processos de estratégia, na medida em que eles ocorreram a trajetória do CMA/ PROPAD foi subdividida em 4 (quatro) fases:

- Fase 01: Eventos anteriores ao CMA/PROPAD (1988-1994);

- Fase 02: Início das aulas/instauração - CMA (1994-1999);

- Fase 03: Estruturação e Expansão - PROPAD (2000-2009);

- Fase 04: Inflexão (2009-2014).

Para a divisão das fases, na medida em que os eventos críticos eram apontados conseguia-se visualizar a quebra de uma fase para outra, decorrente de mudanças provocadas por algum episódio característico.

A formação das estratégias ocorreu tanto do tipo deliberada - fruto de um processo de planejamento consciente (ainda que nem sempre bem disseminado) - quanto de emersão (MINTZBERG; WATERS, 1985; MINTZBERG, 1989) oriundas de um processo de adaptação.

É possível inferir que, de modo geral, as estratégias do CMA/ PROPAD foram deliberadas quando passaram pelos processos de planejamento formal, ainda que nem sempre disseminadas e concebidas de modo colaborativo. Foram emergentes quando oriundas de um processo de adaptação. Consideramos oportuno mencionar que foi possível perceber a influência do contexto nas 
mudanças estratégicas, sobretudo do externo. Apesar da própria fundação do programa ter caráter proativo, o ambiente externo caminhava nessa direção e experimentava um momento de expansão no ensino superior.

Diante desse estudo, espera-se contribuir com reflexões para que outros programas de pós-graduação possam utilizar das estratégias para melhor conhecer o curso de suas ações e resgatar registros históricos também denominados de memória institucional.

Como principais limitações, vale ressaltar que, diante do foco no objetivo do estudo com as escolhas das lentes teóricas e metodologia, pouco ou nada foi explorado do contexto político e econômico nacional diante do corte de recursos e que no período do estudo outros cursos de pós-graduação e iniciativas diversas envolvendo ensino na graduação, projetos de internacionalização e representações internas em conselhos e comissões assim como externas como FACEPE, CAPES e CNPq para citar algumas, foram constituídos demandando esforços divididos. Demandas da estrutura oriunda do Departamento de Ciências Administrativas, criado em 1975 para atender ao Curso de Administração iniciado dez anos antes. Em síntese, antes de 1995 as atividades de ensino, pesquisa e extensão envolviam lecionar disciplinas de Administração nos cursos de graduação, as poucas pesquisas recebiam bolsas PIBIC como fomento e organização/participação em eventos. Outro estudo poderia incluir narrativas de docentes que vivenciaram tal processo de formação de estratégias sem fazer parte da pós-graduação, complementando o material analisado.

Finalizando, as reflexões aqui iniciadas fomentam contínuos diálogos tanto sobre e no ambiente social da investigação abordada no texto quanto para os demais, sejam no mesmo período de 1994 a 2014, 2015 ao momento atual ou ainda para perspectivas futuras.

\section{REFERÊNCIAS}

ALVES, D.; FIGUEIREDO FILHO, D. B.; SILVA, A. H. O poderoso NVivo: Uma introdução a partir da análise de conteúdo. Revista Política Hoje, v. 24, n. 2, p. 119-134. Recife, 2015.

ANDRADE, A. R. A universidade como organização complexa. Revista de Negócios, v. 7, n. 3, p. 15-28, jul./set.Blumenau, 2002. 
ANDREWS, K. R. The Concept of Corporate Strategy. Homewood, Illinois: Down JonesIrwin, 1971.

ANSOFF, H. I. Corporate strategy: An analytic approach to business policy for growth and expansion. New York: McGraw-Hill Companies,1965.

ARAÚJO S., F.; GONÇALVES, C. A. O processo de formulação e implementação de planejamento estratégico em instituições do setor público. Revista de Administração da UFSM, v. 4, n. 3, p. 458-47. Rio Grande do Sul, 2011.

AUGUSTO, C. A.; SOUZA, J. P.; DELLAGNELO, E. H. L.; CARIO, S. A. F. Pesquisa Qualitativa: rigor metodológico no tratamento da teoria dos custos de transação em artigos apresentados nos congressos da Sober (2007-2011). Revista de Economia e Sociologia Rural, v. 51, n. 4, p. 745-764. Brasília, 2013.

BALDRIDGE, J. V. Estructuración de políticas y liderazgo efectivo en la educación superior. Mexico: Noema Editores SA, 1982.

BAUER, M. W.; GASKELL, G. Pesquisa qualitativa com texto, imagem e som: um manual prático. Petrópolis: Vozes, 2002.

BOGDAN, R. C.; BIKLEN, S. K. Investigação qualitativa em educação. Porto: Editora Porto, 1994.

BRASIL. Parecer CFE no 977/65, aprovado em 3 dez. 1965. Revista Brasileira de Educação, n. 30, p. 162-173, set./out./nov./dez. 2005.

BUCKLAND, R. Private and Public Sector Models for Strategies in Universities. United Kingdom: British Journal of Management, Vol. 20, p. 524-536, 2009.

BULGACOV, S.; SOUZA, Q. R.; PROHMANN, J. I. P.; COSER, C.; BARANIUK, J. Administração estratégica: teoria e prática. São Paulo: Atlas, 2007.

CAPES. História e Missão. Disponível em: <http://www.capes.gov.br/historia-e-missao>. Acesso em: 10 jul. 2017.

CASARTElli, A. O.; RODRIGUES, A. C. de M.; BITTENCOURT, H. R.; GARIBOTTI, V. Inteligência estratégica em instituições de ensino superior. Perspectivas em Ciência da Informação, v. 15, n. 2, p. 183-197, maio/ago. Belo Horizonte, 2010.

CAVAlEIRO, K. C. L. M.; BARROS NETO, J. P. Contexto, Conteúdo e Processo da Mudança Estratégica em uma Entidade de Classe da Indústria Brasileira. Revista Alcance, v. 23, n. 3, p. 372, Itajaí, 2016.

CHANDLER, A. Strategy and structure. Cambridge, Ma: MIT Press, 1962.

COSTA, E. A. C. Gestão estratégica. São Paulo: Saraiva, 2005.

CRESWELL, J. W. W. Projeto de pesquisa: métodos qualitativo, quantitativo e misto. 2. ed. Porto Alegre: Bookman, 2010.

CUNHA, C. J. C. A. Adaptação Estratégica em Ambiente Turbulento. Florianópolis. Tese para concurso de professor titular - Programa de Pós-Graduação em Engenharia de Produção - Departamento de Engenharia de Produção e Sistemas, UFSC. Florianópolis, 1996. 
DENZIN, N. K.; LINCOLN, Y. S. Introdução: a disciplina e a prática da pesquisa qualitativa. In: DENZIN, N. K. e LINCOLN, Y. S. (Orgs.). O planejamento da pesquisa qualitativa: teorias e abordagens. 2. ed. Porto Alegre: Artmed, 2006. p. 15-41.

DeWIT, B; MEYER, R. Strategy: Process, Content and Context. Italy: Thomson, 2004.

FLICK, W. Introdução à pesquisa qualitativa. Tradução Joice Elias Costa. 3. Ed. Porto Alegre: Artmed, 2009.

GODOY, A. S. Estudo de caso qualitativo. In: GODOI, C.K.; BANDEIRA-DE-MELO, R.; SILVA, A. B. (org). Pesquisa qualitativa em estudos organizacionais: paradigmas, estratégias e métodos. 2 ed. São Paulo: Saraiva, 2010.

GOHR, C. F.; SANTOS, L. C. Contexto, conteúdo e processo da mudança estratégica em uma empresa estatal do setor elétrico brasileiro. Revista de Administração Pública, Rio De Janeiro, v. 6, n. 45, p. 1673-1706, dez. Rio de Janeiro, 2011.

GOMES, F. P.; MEYER Jr., V. Formação de Estratégias: Uma Análise Sob as Lentes da Teoria da Complexidade. V Encontro de Estudos em Estratégia. Porto Alegre, 2011.

HAMBRICK, D. C. Operationalizing the concept of business-leel strategy in research. Academy of Management Review, vol. 5, no 4, New York,1980.

JOHNSON, G. Managing strategic change: strategy, culture and action. Long Range Planning. v. 25, fev. United Kingdom, 1992.

KERCH, A. L. Educação superior em administração no Brasil. In: ENCONTRO NACIONAL DE CURSOS DE ADMINISTRAÇÃO, 34., Florianópolis, 2013. Anais... Florianópolis: ENANGRAD, 2013.

LINCONL, Y. S.; GUBA, E .G. Naturalistic inquiry. Londres: Sage Publications, Inc., 1985.

LINS, M. P. P. A pragmática e a análise de textos. Revista (Con)textos Linguísticos, v. 2, n. 2, p. 158-176, Vitória/ES, 2008.

LUDKE, M.; ANDRÉ, M. E. D. A. Pesquisa em educação: abordagens qualitativas. São Paulo: E.P.U., 1986.

MACEDO, R. Z. Estratégias adotadas pelas instituições de ensino superior da rede privada face às transformações no início do século XXI. 2011. (Dissertação de Mestrado). Faculdade de Pedro Leopoldo, Pedro Leopoldo - MG, 2011.

MANZINI, E. J. Entrevista: definição e classificação. Marília: Unesp 4, 2004.

MARRA, A. V.; MELO, M. C. de O. L. Docente gerente: o cotidiano de chefes de departamento e coordenadores em uma Universidade Federal. ENCONTRO NACIONAL DE PROGRAMAS DE PÓS-GRADUAÇÃO EM ADMINISTRAÇÃO, 27, 2003, Curitiba. Anais... Curitiba: ENANPAD, 2003.

MARTINS, C. B. A reforma universitária de 1968 e a abertura para o ensino superior privado no Brasil. Educação \& sociedade, Campinas, v. 30, n. 106, 2009.

MARTINS, C. B. Surgimento e expansão dos cursos de administração no Brasil (1952-1983). Ciência e Cultura, São Paulo, v. 41, n. 7, p. 663-676, jul. 1989. 
MATTOS, P. L. C. L. Análise de entrevistas não estruturadas: da formalização à pragmática da linguagem. In: SILVA, A. B.; GODOI, C. K.; BANDEIRA-DE-MELO, R. (orgs). Pesquisa qualitativa em estudos organizacionais: paradigmas, estratégias e métodos. 2. ed.São Paulo, p. $347-374,2010$.

MELIN, L. Internationalization as a strategic process.Strategic Management Journal, v. 13, n. 8, p. 99-118, 1992.

MEYER JR, V., LOPES, M. C. B., ZABLONSKY. M. J., MURPHY, J. P. Enrollment management as competitive strategy in private community universities. Estratégia e Negócios, 3(1), p. 123-143, Florianópolis/SC, 2010.

MEYER JR, V.; MUGNOL, G. Competição e estratégia no contexto das instituições de ensino superior privadas. Revista Diálogo Educacional, .Curitiba: Editora Champagnat, vol. 4. no 11, p. 153-165. Curitiba/PR, 2004.

MILLER, D.; FRIESEN, P. H. Innovation in conservative and entrepreneurial firms: Two models of strategic momentum. Strategic management journal, v. 3, n. 1, p. 1-25. New York, 1982.

MINAYO, M. C. S. O desafio do conhecimento: pesquisa qualitativa em saúde. 12 ed. São Paulo:Hucitec: 2010.

MINTZBERG, H. Mintzberg On Management: inside our strange world of organizations. New York: The Free Press, 1989.

MINTZBERG, H., AHLSTRAND, B., LAMPEL, J. Safári de Estratégias: um roteiro para a selva do planejamento estratégico. 2a ed. Porto Alegre: Bookman, 2010.

MINTZBERG, H., LAMPEL, J., QUINN, J. B., GHOSHAL, S. O Processo da Estratégia: conceitos, contextos e casos relacionados. 4a ed. Porto Alegre: Bookman, 2006.

MINTZBERG, H.; QUINN, J. B. O processo da estratégia. Porto Alegre: Bookman, 2001.

MINTZBERG, H.; ROSE, J. Strategic Management Upside Down: Tracking Strategies at McGill University from 1829 to 1980. Canadian Journal of Administrative Sciences. v.20, n.4 Dec. Montreal, 2003.

MINTZBERG, H; WATERS, J.Of strategies, deliberate and emergent. Strategic Management Journal, v. 6, n. 3, p. 273-293. New York, 1985.

MONTEIRO, L. A. S. A pós-graduação lato sensu em Administração no Brasil: um estudo de caso. In: COLÓQUIO INTERNACIONAL SOBRE GESTÃO UNIVERSITÁRIA NA AMÉRICA DO SUL, 8., 2008, Assunção (Paraguai). Anais... Assunção: UFSC, 2008.

MOORE, M. H. Managing for value: organizational strategy in for-profit, nonprofit, and governmental organizations. Nonprofit and Voluntary Sector Quarterly, v. 29, n. 1, p. 183204. London, 2000.

MOROSINI, M. C. A pós-graduação no Brasil: formação e desafios. Revista Argentina de Educación Superior, v. 1, n. 1, p. 125-15. Buenos Aires, 2009.

MOZZATO, A. R.; GRZYBOVSKI, D. Análise de conteúdo como técnica de análise de dados qualitativos no campo da administração: potencial e desafios. Revista de Administração Contemporânea, v. 15, n. 4, p. 731-747. Rio de Janeiro, 2011. 
NICOLAU, I. O conceito de estratégia. Lisboa: INDEG, 2001.

OLIVEIRA, V. M.; MARTINS, M. F.; VASCONCELOS, A. C. F. Entrevistas “Em Profundida$\mathrm{de}^{\prime \prime}$ na pesquisa qualitativa em administração: Pistas teóricas e metodológicas. Simpósio de Administração da Produção, Logística e Operações Internacionais-SIMPOI, v. 15, p. 1-12. São Paulo: FGV/EAESP, 2012.

PAIVA JR, F. G.; LEÃO, A. L. M. S.; MELLO, S. C. B. Validade e confiabilidade na pesquisa qualitativa em Administração. Revista de Ciências da Administração. v.13, n.31, p.190-209, set/dez, 2011.

PETTIGREW, A. M. Context and action in the transformation of the firm. Journal of management studies, v. 24, n. 6, p. 649-670. New York, 1987.

PINTO, V. R. R.; MOTTER JUNIOR, M. Uma abordagem histórica sobre o ensino da Administração no Brasil. Revista Pensamento Contemporâneo em Administração, v. 6, n. 4, p. 1-28. Niterói, 2012.

QUINN, J. B. Strategies for change: Logical incrementalism. New York: Irwin Professional Publishing, 1980.

SALAZAR, V. S.; MORAES, W. F. A.; LEITE, Y. V. P. “Era uma vez...": processo de formação das estratégias dos restaurantes gastronômicos na América Latina. Revista: Turydes Revista Turismo y Desarrollo, v. 9, p. 1-11. Málaga, 2016.

SANTOS, A. L. F.; AZEVEDO, J. M. L. A pós-graduação no Brasil, a pesquisa em educação e os estudos sobre a política educacional: os contornos da constituição de um campo acadêmico. Revista Brasileira de Educação, v. 14, n. 42, p. 535. Rio de Janeiro, 2009.

SCARPIN, M. R. S.; DOMINGUES, M. J. C. S.; SCARPIN, J. E. Fatores de atração como diferencial competitivo nos cursos de pós-graduação lato sensu. In: SEMINÁRIOS EM ADMINISTRAÇÃO (SEMEAD), 13., 2008, Rio de Janeiro. Anais... Rio de Janeiro: UFRJ, 2008.

SEVERINO, A. J. A avaliação no PNPG 2005-2010 e a política de pós-graduação no Brasil. In: FERREIRA, NauraSyriaCarapeto (Org.). Políticas públicas e gestão da educação: polêmicas, fundamentos e análises.p. 51-74. Brasília: Líber Livro, 2006.

SILVA, L. K. S. Processo de Formação de Estratégias nos Vinte Anos do PROPAD - 1994/2014. (Dissertação de Mestrado) Universidade Federal de Pernambuco, Recife - PE, Brasil, 2017.

SILVA, M. A.; MORAES, L. V.S. Como os professores aprendem a dirigir unidades universitárias: o caso da UFSC. In: ENCONTRO NACIONAL DOS PROGRAMAS DE PÓS-GRADUAÇÃO EM ADMINISTRAÇÃO, 26, 2002, Atibaia. Anais... Atibaia: ENANPAD, 2002.

SILVA, R. H. R. A Educação especial no âmbito da pós-graduação em educação no Brasil. UFG e UNICAMP - 2010. Disponível em: http://www.anped.org.br/33encontro/app/webroot/ files/file/P\%C3\%B4steres\%20em\%20PDF/GT15-6140--Int.pdf. Florianópolis, Santa Catarina, Brasil. Acessado em 03 de dez. 2016.

SOUZA, S., SILVA, A. R. L., SILVA JÚNIOR, A., SILVA, P. O. M. O processo de formação de estratégias na instituição de educação superior privada: múltiplos interesses articulados no formalismo. REGE, 19(3), 435-452, 2012. 
STAKE, R. E. Pesquisa Qualitativa: estudando como as coisas funcionam. Porto Alegre: Artmed/Penso, 2011.

TASCA, G. G.; COSTA, L. F. L. G. Processo de formação das estratégias de internacionalização: estudo de caso da FINOBRASA. HOLOS, v. 6, p. 355-367, Natal, 2015.

UFPE. Universidade Federal de Pernambuco. Acesso à informação. 2016. Disponível em: $<$ https://www.ufpe.br/ufpenova/>. Acesso em: 15 jul. 2017.

VIEIRA, A. M.; RIVERA, D. P. B. A Hermenêutica no Campo Organizacional: duas possibilidades interpretativistas de pesquisa. Revista Brasileira de Gestão de Negócios, v. 14, n. 44, p. 261-273, 2012.

WAIANDT, C.; FISCHER, T. O ensino dos estudos organizacionais nas instituicoes brasileiras: um estudo exploratório nos cursos de pós-graduação stricto sensu de administração. Administração: Ensino e Pesquisa-RAEP, v. 14, n. 4, p. 807-837, Rio de Janeiro, 2013.

WEICK, K. E. Educational organizations as loosely coupled systems. Administrative Science Quarterly, v. 21, p. 1-19, New York,1976.

WITTGENSTEIN, L. Tractatuslogico-philosophicus. São Paulo: Edusp, 1994.

Recebido em: 17-2-2018

Aprovado em: 23-10-2018

Avaliado pelo sistema double blind review.

Editor: Coordenação do PPGA/UMESP

Disponível em http://mjs.metodista.br/index.php/roc 